\title{
The problem solving strategy of poor core stability in children with cerebral palsy: a clinical trial
}

\begin{abstract}
Sitting is the earliest upright posture that is achieved during the normal development. The capacity to maintain balance in sitting is a pre-requisite to the activities of daily living. Core stability is the ability to control position and movement of central portion of the body. Children with cerebral palsy have poor central control which affects sitting balance. Although core stability is important for sitting balance, there are scarce studies that demonstrate core stability training in cerebral palsy.
\end{abstract}

Purpose: to study the effect of core stability training program on sitting control in children with cerebral palsy and to design a problem solving strategy for poor core stability based on Neuro-Developmental Therapy (NDT)

Subjects: 26 spastic diplegic children were divided into two groups; the group A; 12 children with a mean age $(2.45 \pm 0.86)$ and group B; 14 children with a mean age (2.57 \pm 0.97$)$. Group A received selected physical therapy program while Group B received an especially designed physical therapy program for core stability based on the NDT. Both groups received therapy for one hour, three times weekly for successive two months.

Methods: the functional motor skills were evaluated using the Gross Motor Function Measure (GMFM) scale before and after the treatment.

Results: The paired t-test revealed that the gross motor function of children from both groups improved significantly after two months of treatment in both lying and sitting domains $(\mathrm{P}=0.04$ for lying and $\mathrm{P}=0.001$ for sitting domain in group $\mathrm{A}$ while group $\mathrm{B} \mathrm{P}=$ 0.0001 in lying and sitting domains). The unpaired t-test revealed that the children in group $\mathrm{B}$ performed better and showed significantly greater improvement than those in group A $(\mathrm{P}=0.004$ in lying and 0.02 in sitting domain)

Conclusion: The core stability is essential for postural sitting control. Neuro-developmental therapy is a valuable approach for improving functional sitting outcomes.

Keywords: problem solving strategy, core stability, cerebral palsy, clinical trial
Volume I Issue 6 - 2014

\author{
Mai Abd El Mohsen Ahmed,' Faten Hassan \\ Abd El Azeim,' Ehab Ragaa Abd El Raouf² \\ 'Department of Growth and Developmental Disorders in \\ Children and Its Surgery, Cairo University, Egypt \\ ${ }^{2}$ National Research Center, Cairo University, Egypt
}

Correspondence: Faten Hassan Abd El Azeim, professor of physical therapy, Department of Growth and Developmental Disorders in Children and Its Surgery, Cairo University, 7 Ahmed Elzayat St, Doky, Giza, Egypt, Tel 10085548I8, Fax +203 376I7692, Email Faten.Hassan@pt.cu.edu.eg

Received: August 31, 2014 | Published: October 28, 2014
Abbreviations: CP, cerebral palsy; GMFCS, gross motor function classification system; GMFM, gross motor function measure; MAS, modified ashworth scale; NDT, neuro-developmental therapy/treatment; NS, non-significant; NWB, non weight bearing; $\mathrm{P}$, probability; S, significance; $\mathrm{SD}$, standard deviation; $\mathrm{WB}$, weight bearing; CNS, central nervous system; DLA, daily living activities

\section{Introduction}

Cerebral palsy (CP) is defined as "a group of disorders of the development of movement and posture causing activity limitation due to non-progressive disturbances that occurred in the developing fetal or infant brain. ${ }^{1}$ Children with $\mathrm{CP}$ are functionally limited to varying degrees because of their decreased central control and coordination of their movements. ${ }^{2}$ They demonstrate limitation in postural mechanisms, as deficits in postural reactions, antigravity movement, proximal muscle co-contraction and stability in upright postures. ${ }^{3}$ Sitting is an important step for child to achieve the upright posture against gravity which provides the postural tone required for the upper limb activities. ${ }^{4}$ The ability to sit independently is fundamental for function but delayed in infants with CP. Studies of interventions directed specifically toward sitting in infants with $\mathrm{CP}$ have not been reported. ${ }^{5}$

"Core stability" explains the capacity to control the position and movement of the central portion of the body. Core stability training targets the muscles deep within the abdomen that attach to the spine, pelvis and shoulders, that help in the preservation of proper posture and provide the basis for movements of extremities. Spinal stability is essential for the production of movement and relies on the core muscles to acquire sufficient strength, power, and endurance. ${ }^{6}$ The core has illustrated by researchers as a "power-house" for initiating limb movement or as a double-walled cylinder or box in which the abdominals act as the front of the house, the paraspinals serve as the back, the diaphragm serves as the roof, and the musculature of the hip girdle and pelvic floor create the 2 basement of the house. ${ }^{7,8}$ Contraction of core muscles provides a basis for the naturally unstable spine, and allows forces between body parts to transfer during dynamic movements. ${ }^{6,-12}$ (Figure 1). ${ }^{13}$

Leetun et al. ${ }^{14}$ noted that motor control and muscular capacity build core stability. Others stated that core stability involves many components like core strength, endurance, power, balance, and the coordination of the spine, abdominal, and hip muscles. ${ }^{15,16}$ The core resembles a muscular corset that works as a unit to stabilize the body specially the spine with and without movement of extremities. ${ }^{17}$ Core activity doesn't involved only in spinal stability and force generation but also it is involved in most of activities of upper and lower limbs. ${ }^{18}$

The study aimed to study the effect of core stability training on sitting control in children with cerebral palsy and to design a problem solving strategy for poor core stability based on NDT. Clarifying 
way of thinking in analysis, problem solving of poor core stability in children with cerebral palsy and its influence on sitting postural control may help physical therapists to approach this problem properly.

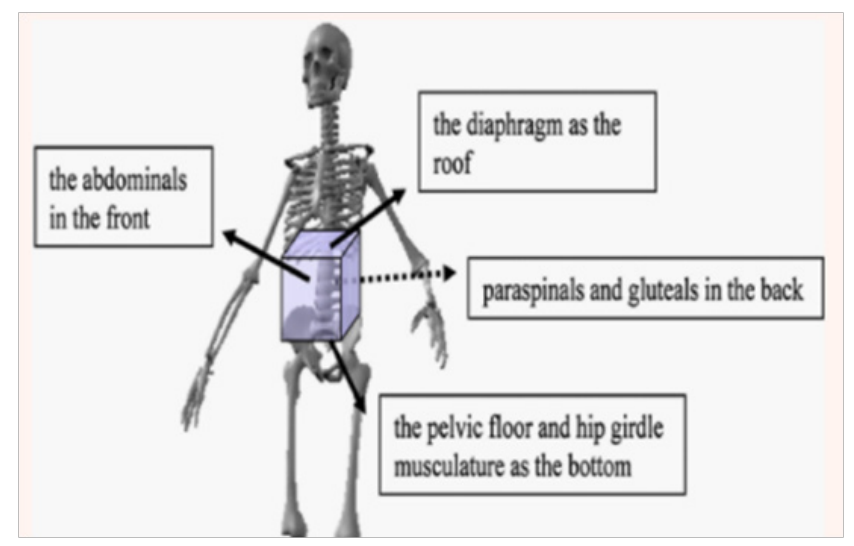

Figure I The core musculature box (Miyake et al. ${ }^{13}$ ).

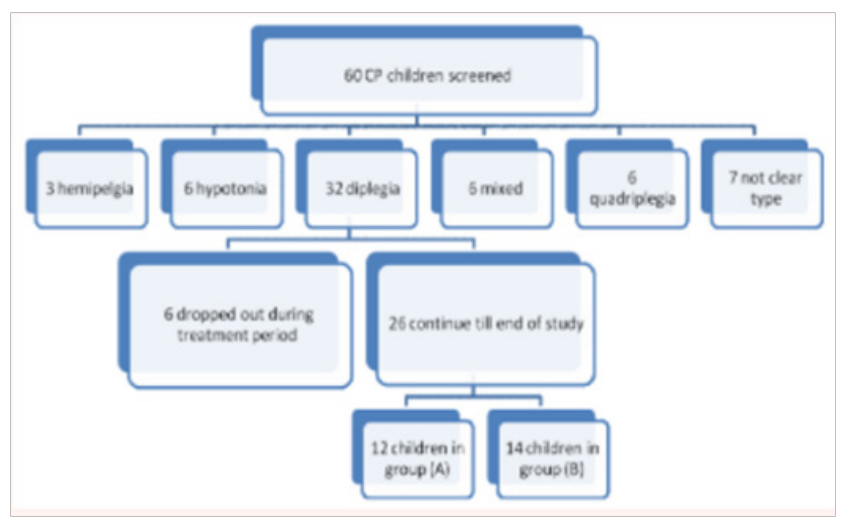

Figure $\mathbf{2}$ The flow chart of recruitment and group assignment of children in the study.

\section{Methods}

\section{Subjects}

The twenty six spastic diplegic CP children -that completed the study till end-were divided into two groups; group A contained 12 children while group B contained 14 children while the therapist wasn't blinded. Parents of all children who participated in this study filled out a written consent before the study.

The selected children were classified as level IV according to Gross Motor Function Classification System (GMFCS). They were grade 1/1+ (mild spasticity) according to Modified Ashworth Scale (MAS). Their ages were from 1 year to 4 years old. They were chosen regardless the cause of $\mathrm{CP}$. They have deformities in neither shoulder nor hip joints. They have no structural scoliosis.

\section{Procedure}

GMFM was used to examine lying and sitting domains as a reflection of core stability. Lying domain of GMFM contains 17 items that cover different activities from supine and prone positions that reflect impact of core training on stability of proximal joints. Sitting domain of GMFM examines different sitting patterns. Sitting domain contains 20 items which cover different sitting patterns as cross sitting, long sitting and sitting on high and low level chair and transferring in and out sitting position. Gross motor function measure scale was administrated in an environment that was comfortable for the child and was large enough to hold necessary equipment and allow the child to move freely. Patients were instructed to wear very comfortable and light clothes as t-shirt and short, considering closed warm environment. The recording sheet of every subject was filled out during evaluation with calculation of total score of each domain according to manual of GMFM.

All children received physical therapy sessions for one hour in each, three times per week for successive two months. The children in group A received traditional physical therapy program based on mechanical concept through using static sitting positions and gradual active strengthening exercises for the trunk. While children in group $B$ received a specially designed physical therapy program to improve core stability based on NDT.

\section{Data analysis and statistical design}

The data were collected before and after two months of training for all children who participated in this study. The data obtained was statistically analyzed.

\section{Descriptive statistics}

The mean and standard deviation were calculated for each variable before and after two months of the treatment for both groups.

\section{Inferential statistics}

Unpaired t-test between groups and paired t-test within the group were used to compare the results of both groups before and after two months. P-value was considered to be clinically statistically significant if it less than 0.05 and it was set with two tailed test. The following variables were measured: i. Total score of both (lying \& rolling) and (sitting) domains in form of goal functional area which includes 37 items. ii. Static items of GMFM within lying and sitting domains which include items 21-24, 28-29 and 34 . iii. Dynamic items of GMFM within lying and sitting domains which include items 1-20, 25-27, 30-33, 35-37. iv. Items of lying and sitting domains that reflect shoulder stability from non-weight bearing (NWB) positions which include items 2, 6-9, 25-27.

v. Items that reflect shoulder stability from weight bearing (WB) positions which include items 11-17, 19-20, 23, 30-32, 35-37.

\section{Results}

Sixty children of both sexes were screened before the study through GMFM scale as presented in the flow chart. Spastic diplegic type was selected as it was the commonest type during the pretreatment assessment. The paired t-test revealed that the gross motor function of children from both groups improved significantly after two months of treatment in both lying and sitting domains $(\mathrm{P}=0.04$ for lying and $\mathrm{P}=0.001$ for sitting domain in group $\mathrm{A}$ while group $\mathrm{B}$ $\mathrm{P}=0.0001$ in the two domains). The unpaired t-test revealed that the children in group B performed better and showed significantly greater improvement than those in group $\mathrm{A}(\mathrm{P}=0.004$ in lying and 0.02 in sitting domain) as shown in Table 1 (Figure 2).

\section{Discussion}

There was a significant improvement after two months of treatment in both groups with significant difference in favor of group B when compared to group A. This significant improvement in GMFM scores 
for both groups after intervention might be due to improvement of trunk muscles strength through activation of abdominal and back muscles in different tasks. This comes in agreement with results of
Park et al14 who concluded that, trunk control and sitting posture get better with stimulation of back and abdominal muscles at the same time.

Table I Paired and unpaired comparisons of the tested variables

\begin{tabular}{|c|c|c|c|c|c|c|c|c|c|c|c|c|c|c|c|}
\hline & \multicolumn{3}{|c|}{$\begin{array}{l}\text { Total Score of Lying \& } \\
\text { Sitting Domains }\end{array}$} & \multicolumn{3}{|c|}{$\begin{array}{l}\text { Static Items of Lying \& } \\
\text { Sitting Domains }\end{array}$} & \multicolumn{3}{|c|}{$\begin{array}{l}\text { Dynamic Items of Lying \& } \\
\text { Sitting Domains }\end{array}$} & \multicolumn{3}{|c|}{$\begin{array}{l}\text { Items for Shoulder Stability } \\
\text { from WB }\end{array}$} & \multicolumn{3}{|c|}{$\begin{array}{l}\text { Items for Shoulder } \\
\text { Stability from NWB }\end{array}$} \\
\hline & Pre & Post & $P$ within & Pre & Post & $P$ within & Pre & Post & $P$ within & Pre & Post & $P$ within & Pre & Post & $P$ within \\
\hline Group A & $\begin{array}{l}61.79 \\
\pm 16.28\end{array}$ & $\begin{array}{l}70.57 \pm \\
19.21\end{array}$ & 0.02 & $\begin{array}{l}13.65 \\
\pm \\
4.57\end{array}$ & $\begin{array}{l}15.38 \\
\pm 4.23\end{array}$ & $0.01 *$ & $\begin{array}{l}46.5 \pm \\
12.83\end{array}$ & $\begin{array}{l}54.9 \pm \\
13.5 \mid\end{array}$ & $0.0001 *$ & $\begin{array}{l}20.0 \pm \\
7.04\end{array}$ & $\begin{array}{l}25.24 \pm \\
7.12\end{array}$ & $0.005^{*}$ & $\begin{array}{l}15.04 \\
\pm \\
6.19\end{array}$ & $\begin{array}{r}17.16 \\
\pm 5.54\end{array}$ & $0.006 *$ \\
\hline Group B & $\begin{array}{l}60.25 \\
\pm 16.77\end{array}$ & $\begin{array}{l}85.7 \pm \\
10.94\end{array}$ & $0.0001 *$ & $\begin{array}{l}13.03 \\
\pm \\
4.22\end{array}$ & $\begin{array}{l}18.66 \\
\pm 1.92\end{array}$ & $0.0001 *$ & $\begin{array}{l}45.19 \pm \\
13.48\end{array}$ & $\begin{array}{l}65.57 \pm \\
8.32\end{array}$ & $0.0001 *$ & $\begin{array}{l}19.47 \\
\pm 7.78\end{array}$ & $\begin{array}{l}32.64 \pm \\
6.23\end{array}$ & $0.000 I^{*}$ & $\begin{array}{l}14.79 \\
\pm \\
4.83\end{array}$ & $\begin{array}{r}20.77 \\
\pm 1.98\end{array}$ & $0.0001 *$ \\
\hline $\begin{array}{l}P \\
\text { between }\end{array}$ & 0.81 & $0.02 *$ & & 0.72 & $0.01 *$ & & 0.8 & $0.02 *$ & & 0.85 & $0.009^{*}$ & & 0.91 & $0.03 *$ & \\
\hline
\end{tabular}

$\mathrm{P}$-value $<0.05$ is considered to be statistically significant

SD: Standard Deviation; P: Probability; *: Significant

Also these significant changes might be due to improve trunk control through focusing on different sitting patterns. This comes in agreement with outcome of Harbourne et al. ${ }^{5}$ who reported that targeting the intended task (sitting) during intervention develops considerable changes in the task behavior. In addition, Blundell et al. ${ }^{19}$ reported that long term functional goals may be developed by strengthening exercises in CP children as those children have limited chance to practice different movement patterns against gravity to develop the proper power, endurance and preserve energy that consumed in other compensatory movement. Postural reactions were facilitated in different tasks for both groups might help in improvement of antigravity mechanism that helps those children to control an upright posture like sitting. This comes in agreement with the findings of Mayston and Margaret ${ }^{20}$ who warned that children with $\mathrm{CP}$ may control floor activities perfectly but have poor control on antigravity positions due to lack of postural reactions.

By observation of post-study measurements; there is a significant improvement in GMFM scores in favor of group B after two months of treatment as compared to group A in all measured variables. This improvement might be due to facilitation techniques that were selected to group B according to neuro-developmental therapy. ${ }^{21}$ The child was facilitated during sessions through placing therapist hands on particular parts of child body to align, stabilize, initiate movement, and/or prevent movement of specific body segment. This comes in agreement with results of Harbourne et al. ${ }^{5}$ who recommended perceptual-motor intervention with $\mathrm{CP}$ children clarifying that building a skill requires initiation of action by the child while therapist guides child and decreases that guide gradually.

Tactile sensation and proprioception were stimulated through therapist's hands/ body and equipment while vestibular sensation was stimulated through performing different tasks using movable equipment like a ball or bolster. This is supported by Hain and Hillman $^{22}$ who stressed that the vestibular system has the most significant impact on other sensory systems and on the capability to function in daily life. Also Liemohn et al. ${ }^{15}$ used cues to lead the child to use particular tactile, proprioceptive, and pressure information to achieve the intended task instead of depending on assistance from the therapist. The child was encouraged to move in three planes of movements (frontal, sagittal and transverse) in different tasks. Especially transverse plane as it is the first to be lost in motor disability though it is the last to develop. This is supported by Frankenburg ${ }^{23}$ who reported that the 4th stage of movement development to develop a skill is the postural control in the three planes of movement.

Most of tasks focus on dynamic activities rather than static positions to facilitate fluidity and smoothness of movement through the organization between and within muscle groups (agonist/antagonist and synergist) which is improper in CP children. This comes in agreement with Bigongiari et al. ${ }^{24}$ who found that $\mathrm{CP}$ children showed stronger single and agonist/antagonist muscle activations comparing to normal children. This was obvious in the current study from the results that dynamic items of lying and sitting domains of GMFM scale were significantly improved in favor of group B as compared to group A.

Dissociation between body parts was considered in different tasks to permit selective control and control on dynamic activities. This comes in agreement with the instruction of Frankenburg23 who highlighted that ability to dissociate movements between body segments is an essential stage of development of movement.

Training was carried out in a functional way to be translated into a skill to facilitate proper development of activities of daily living. This comes in agreement with the finding of Mayston and Margaret ${ }^{20}$ that CNS is task dependent in its organization and improving of patterns of muscle activation alone can't grant the prospect for gaining a new skill. So improving coordination patterns will be in proper significance when they are learnt in the proper functional context. Also training in the current study affords a mechanical advantage through preactivation muscle lengthening which will preserve muscle integrity instead of surgical intervention. Effectiveness of NDT is further supported by the recommendation of Tsorlakis et al. ${ }^{25}$ who stressed upon the effect of intensive neuro-developmental treatment in gross motor function in children with CP.

Many studies provided further evidences supporting NDT as exercises for lower limbs in CP children improve strength and function without increase in spasticity or undesirable movements. This is also evidenced through several studies of stroke patients. ${ }^{19}$ It was assumed previously that effort associated with strengthening exercise increase spasticity, associated reactions and abnormal cocontraction. Core stability training program which was selected to group B might provide another explanation of improvement of sitting postural control in this group when compared to group A. This comes in agreement with recommendation of Sterba et al. ${ }^{26}$ that strengthening 
of core muscles of the trunk and pelvis will improve co-contraction, joint stability, weight shift and encourage postural and equilibrium reactions in children with $\mathrm{CP}$. In addition, Steinberg ${ }^{27}$ demonstrated improvements in strength and stability of the core muscles for unsupported sitting, increased functional mobility for reaching and grasp control in spastic diplegic $\mathrm{CP}$ child.

It was obvious from results that shoulder stability was improved significantly in favor of group B as compared to group A after treatment as training of core muscles not only improve stability of spine and pelvis but also improve stability of shoulder joint. Furthermore Dodd et al. ${ }^{28}$ found that core stabilization and strengthening exercises improve fine motor control due to improve stability of shoulder joint. Also core stability training in the current study improved feedback mechanism which is one of the keys of postural control. This comes in agreement with the finding of Akuthota et al ${ }^{29}$ that stability of the spine depends on muscle strength as well as proper sensory input that informs the central nervous system about body / environment interaction. This provides constant feedback and allows refinement of movement. Therefore core stabilization training considers sensory and motor components related to these systems for proper spinal stabilization.

In contrast, Law et al. ${ }^{30}$ found no significant differences on functions of the hand, quality of upper limb movement and parents' perception of performance of hand activities between NDT group and other group who received regular programs for reaching and grasping. In addition, Dalvand et al.$^{31}$ compared effectiveness of NDT, Continuous Education and education to parents in daily living activities (ADL) in children with cerebral palsy and found that the most effective approach was Continuous Education then education to parents and NDT. Thus, it can be concluded that NDT provides a problem solving strategy for postural control abnormalities in children with CP. This can be achieved through proper functional assessment that is correlated to patient and family needs to set a smart goal. Training should focus on proper handling skills in movement facilitation, considering sensory deficits in CP children, facilitation of normal movement into three planes of movement, focusing on dynamic activities, facilitation of postural reactions, improving dissociation between body parts in different movements and training in a functional context.

\section{Experimental Intervention}

The children in group A received traditional physical therapy program based on mechanical concept through using static sitting positions and gradual active strengthening exercises for the trunk as the following:

- Cross sitting, holding stand bar.

- Sitting on roll, holding stand bar.

- Stoop and recovery from sitting on roll.

- Sitting in corner.

- Cross sitting with hands propping.

- Side sitting with hands propping.

- Manual sitting with unilateral upper limb activities.

- Pull to sit from supine lying position.

- Get to sit from prone lying position through quadruped position.

- Righting and equilibrium from sitting on ball.

- Quadruped position.

- Kneeling position holding stand bar.

While children in group B received a specially designed physical therapy program to improve core stability based on NDT as the following:

$\therefore$ On therapist lap: • Prone to sit with lateral flexion.

- Prone to sit with extension rotation.
- Lateral weight shift / lateral righting from sitting on lap.

$\therefore$ On ball

- Prone to sit.

- Supine to sit.

- Anterior and posterior weight shift from sitting.

- Lateral weight shift from sitting.

- Diagonal weight shift from sitting: rotation with flexion.

- Diagonal weight shift from sitting: rotation with extension.

$\therefore$ On mat:

- Supine to sit.

- Prone to sit.

- Transition from sitting to quadruped.

$\therefore$ On bolster:

- Sitting to prone on bolster: symmetrical hip extension.

- Upper-Extremity anterior-posterior weight shifts from prone on bolster.

- Wheel barrow walking from prone on bolster.

- Upper-extremity lateral and rotational weight shifting.

- Prone to side lying with lower-extremity dissociation.

- Prone to sit on the bolster.

- Lateral weight shifts from sitting on bolster.

- Anterior and posterior weight shift from sitting on bolster.

\section{Study Limitations}

Psychological behavior of some children might interfere with evaluation process and conducting the treatment program which consume extra time. Long time was needed to collect children with intended criteria.

\section{Conclusion}

The core stability is crucial for postural sitting control. NDT provides clues to solve the problem of poor core stability in children with $\mathrm{CP}$ focusing on functional outcomes.

\section{Acknowledgements}

The Authors would like to express their appreciation to all children and their parents who participated in this study with all content and cooperation.

\section{References}

1. Ju YH, Hwang IS, Cherng RJ. Postural adjustment of children with spastic diplegic cerebral palsy during seated hand reaching in different directions. Arch Phys Med Rehabil. 2012;93(3):471-479.

2. Seymour R. Prosthetics and Orthotics: Lower Limb and Spine, Lippincott Williams \& Wilkins, Philadelphia, USA. 2002; pp. 367-426.

3. Wade L, Canning C, Fowler K, et al. Changes in postural sway and performance of functional tasks during rehabilitation after traumatic brain injury. Arch Phys Med Rehabil. 1997;78(10):1107-1111.

4. Park ES, Park CI, Lee HJ, et al. The effect of electrical stimulation of the trunk control in young children with spastic diplegic cerebral palsy. J Korean Med Sci. 2001;16(3): 347-350.

5. Harbourne RT, Willett S, Kyvelidou A, et al. A comparison of interventions for children with cerebral palsy to improve sitting postural control: a clinical trial. Phys Ther. 2010;90(12):1881-1898.

6. Briggs AM, Greig AM, Wark JD, et al. A review of anatomical and mechanical factors affecting vertebral body integrity. Int J Med Sci. 2004;1(3):170-180.

7. Akuthota V, Nadler S. Core strengthening. Arch Phys Med Rehabil. 2004;85(3 Suppl 1):S86-S92. 
8. Richardson C, Jull G, Hodges P, et al. Therapeutic exercise for spinal segmental stabilization in low back pain: scientific basis and clinical approach. Harcourt Brace and Company Limited, London, UK.1999.

9. Essendrop M, Schibye B. Intra-abdominal pressure and activation of abdominal muscles in highly trained participants during sudden heavy trunk loadings. Spine. 2004;29(21):2445-2451.

10. Faries MD, Greenwood M. Core training: stabilizing the confusion. National Strength and Conditioning Association. 2007;29(2): 10-25.

11. Hodges $\mathrm{P}$, Holm AK, Holm S, et al. Intervertebral stiffness of the spine is increased by evoked contraction of transversusabdominus and the diaphragm: in vivo porcine studies. Spine. 2003;28(23):2594-2601.

12. Stanford M. Effectiveness of specific lumbar stabilization exercises: a single case study. The Journal of Manual \& Manipulative Therapy. 2002;10(1):40-46.

13. Miyake Y, Kobayashi R, Kelepecz D, et al. Core exercises elevate trunk stability to facilitate skilled motor behavior of the upper extremities. $J$ Bodyw Mov Ther. 2013;17(2):259-265.

14. Leetun DT, Ireland ML, Willson JD, et al. Core stability measures as risk factors for lower extremity injury in athletes. Med Sci Sports Exerc. 2004;36(6): 926-934.

15. Liemohn WP, Baumgartner TA, Gagnon L. Measuring core stability, $J$ Strength Cond Res. 2005;19(3): 583-586.

16. Cowley PM, Swensen TC. Development and reliability of two core stability field tests. J Strength Cond Res. 2008;22(2):619-624.

17. Zazulak BT, Hewett TE, Reeves NP, et al. The effects of core proprioception on knee injury: a prospective biomechanical epidemiological study. Am J Sports Med. 2007;35(3):368-373.

18. Kibler WB, Uhl TL, Maddux JW, et al. Qualitative clinical evaluation of scapular dysfunction: a reliability study. J Shoulder Elbow Surg. 2002;11(6):550-556.

19. Blundell SW, Shepherd RB, Dean CM, et al. Functional strength training in cerebral palsy: a pilot study of group circuit training classes for children aged 4-8 years. Clin Rehabil. 2003;17(1):48-57.

20. Mayston M, Margaret J. People with cerebral palsy: effects of and perspective for therapy. Neural plasticity. 2001;8(1-2):51-69.
21. Bly L. Baby Treatment Based on NDT Principles, Therapy Skill Builders. 2008;pp.139-163, 183-202.

22. Hain TC, Hillman M. Anatomy and physiology of the normal vestibular system. In: Herdman SJ editor Vestibular rehabilitation. F.A. Davis Company, Philadelphia, USA. 2005;p. 3-21.

23. Frankenburg M. Motor development. In: Snow CW editor Infant development. 2nd edn, Prentice Hall, New Jersey, USA. 2004;p. 152.

24. Bigongiari A, Souza F, Franciulli P, et al. Anticipatory and compensatory postural adjustments in sitting in children with cerebral palsy. Hum Mov Sci. 2011;(30):648-657.

25. Tsorlakis N, Evaggelinou C, Grouios G, et al. Effect of intensive neurodevelopmental treatment in gross motor function of children with cerebral palsy. Dev Med Child Neurol. 2004;46(11): 740-745.

26. Sterba JA, Rogers BT, France AP, et al. Horseback riding in children with cerebral palsy, effect on gross motor function. Dev Med Child Neurol. 2002;44(5):301-308.

27. Steinberg H. Use of modified core strengthening and stabilization exercises in conjunction with Dynamic Movement Orthoses (DMO) to increase trunk control and grasp control in a 12 year old boy with spastic diplegic cerebral palsy.2010.

28. Dodd KJ, Taylor NF, Damiano DL. Systemic review of strengthening for individuals with cerebral palsy, Arch Phys Med Rehabil. 2002;83(8):1157-1164.

29. Akuthota V, Ferreiro A, Moore T, et al. Core stability exercise principles, Curr Sports Med Rep. 2008;7(1): 39-44.

30. Law M, Russell D, Pollock N, et al. A comparison of intensive neurodevelopmental therapy plus casting and a regular occupational therapy program for children with cerebral palsy, Developmental Medicine \& child Neurol. 1997;39(10):664-670

31. Dalvand H, Dehghan L, Feizy A, et al. Effect of the Bobath technique, Continuous Education and Education to parents in activities of daily living in children with cerebral palsy in Iran. Hong Kong Journal of Occupational Therapy. 2009;19(1):14-19. 